\title{
Research on Land Use and Land Cover Change - Yining, Xinjiang region for nearly 20 years
}

\author{
YE Jiang \\ School Of Civil Engineering, college Of Earth Sciences \\ Southwest Jiaotong University, Chengdu University of \\ Technology \\ Chengdu,China \\ yejiang@cdut.cn
}

\author{
LIU Hanhu \\ College Of Earth Sciences \\ Chengdu University of Technology \\ Chengdu ,China \\ liuhanhu@cdut.cn
}

\begin{abstract}
This paper utilizes TM\ETM remote sensing images of Yining, Xinjiang from 1990, as well as RS technology to revise and enhance the images and improve images fusion. On the basis of field surveys, remote sensing image interpretation signs of the study area were set up. We extracted information from the combination of automatic classification and visual interpretation, then we established a data on the base of land use / land cover (LUCC)of 1990, 2000, 2010, from which we extracted and analyzed the information of Yining's land use changes. Studies have shown that the rapid growth in demand of construction land and the reduce of agriculturalacreage in the past 20 years in Yining increase the pressure on protection for land resource. Meanwhile, land ecological environment quality has declined, and the relationship between the environments has partially deteriorated.
\end{abstract}

IndexTerms - Remote sensing, interpret, landuse/cover change

\section{INTRODUCTION}

LUCC, one of the two basic factors of the global change, has aroused great attention and the research about it has entered a new stage [1]. In China, the environment has been changed by the rapid development of national economy, the growth of the population, as well as the large consumption of land resources. In order to control and use these resources reasonably and effectively, human beings must be able the grasp the current situation and development of the ecological environment rapidly. Remote sensing technology, which is an important means to realize monitoring of current resources and environment, can get a variety of surface information fast and periodically[2].As regional land use change remote sensing image has been the hottest topics in remote sensing research, domestic and overseas scholars do a lot of researches on it[3].From the point of the research content, mainly focus on the trend of land use change and driving force factors[9]. With the deepening of the research, people gradually realized that the land use/land cover changes will deeply influence to the regional ecological process and ecological environment benefits [4-5]. Therefore, the research of land use/cover and the understand of regional ecological environment is of great significance to maintain the ecological balance [6].

This paper utilizes TMIETM remote sensing images of Yining, Xinjiang from 1990, as well as RS technology to revise and enhance the images and improve images fusion. On the basis of field surveys, remote sensing image interpretation signs of the study area were set up. We extracted information from the combination of automatic classification and visual interpretation, then we established a data on the base of land use / land cover (LUCC)of 1990, 2000, 2010, from which we extracted and analyzed the information of Yining's land use changes. Studies have shown that the rapid growth in demand of construction land and the reduce of agriculturalacreage in the past 20 years in Yining increase the pressure on protection for land resource. Meanwhile, land ecological environment quality has declined, and the relationship between the environments has partially deteriorated.

\section{THE STUdy AREA OVERVIEW}

The study area is located in the western Xinjiang Uygur Autonomous Region (Figure 1), western Tian Shan mountains, Ili river valley in central, Nilka county in the east, west and Yining and Huocheng county border, and Ili river adjacent to the south, and ChaBuZhaEr county and Gong Liu county separated by a river, north depends on KuSeMuQieKe river and Bo Le, with JingHe county border, occupying an area of 3500 square kilometers. The area with Kasi river, BoErBoSongriver, BuLiKai river, JiErGeLang river and other rivers. Belonging to temperate continental arid climate, in winter and spring it is warm and wet, while in summer and autumn it is dry and heat. Temperature difference between day and night is apparent, and meanannualtemperature is $8.4{ }^{\circ} \mathrm{C}$, meanannualprecipitation is 257 millimeters, making it the most humid areas in Xinjiang. The study area of the Ili river valley natural condition is superior, as the advantage of husbandry is apparent, livestock products are rich. It is production base of important food, such as oil, livestock, sugar beet, flax, and fruit.

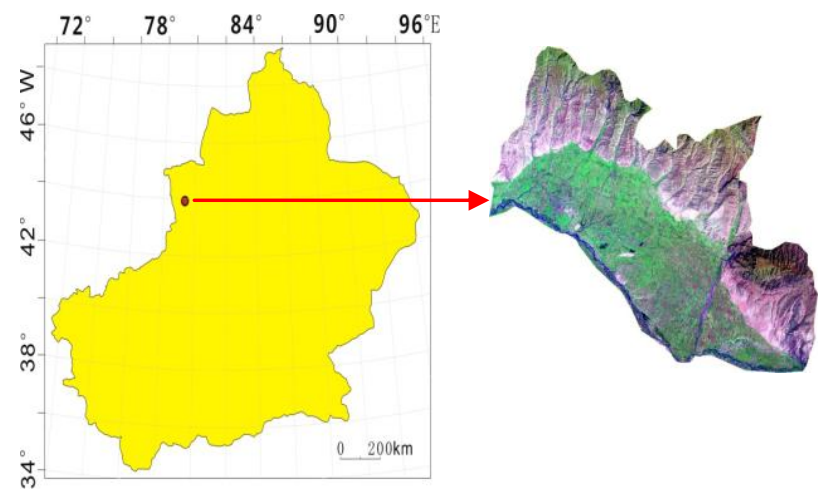

Figure.1 Schematic diagram of the study area range 


\section{REMote SENSING IMAGE DATA SOURCES AND CHARACTERISTICS ANALYSIS}

At present, the commonly used optical remote sensing image data mainly includes: high resolutionQuickbird, Worldview class of images, moderate resolution ALOS, SPOT, P5 class of 2.5 to 10 meters images,Low resolution TM/ETM, ASTER class of 15 to 30 meters images, with a relatively complete historical data and remote sensing data.

The overall image is clear, with strong administrative levels, good color contrast and texture detail. In addition, the author referred to satellite images of the study area from GoogleEarth QUICKBRID.

\section{LAND USE CLASSIFICATION SYSTEM}

Land use/cover change (LUCC) is considered to be one of the most important ways for human beings to effect the environment they live in. However to make land use cover change human factors gradually is considered to be a key factor of causing the global environmental change. In recent years, through the research of land use/cover change on the impact of ecological environment effect, it has become the important method to study the effects of ecological and environmental change.

This research adopts the land use classification system in "The National Land Use Classification System" (GB/T210102007), on the basis of combining with the characteristics of Xinjiang region land use and the established secondary classification system. Among them, Level 1 is divided into three broad categories, 2 points 15 sub-types. Referred to land classification system, according to research needs, the land type divided into eight classes, respectively for the paddy field and dry field, forest land, grassland, wetland, water, land for urban and rural areas, and unused. Consolidation types and their corresponding standard type are shown in (Table I).

\section{THE ESTABLISHMENT OF THE REMOTE SENSING INTERPRETATION SIGNS}

Remote sensing image interpretation signs are called the interpretation elements, referring to the different features on the images reflect the image features, solutions the translator can use the logo on the image to identify the nature of the object or phenomenon, type, or status. Remote sensing image interpretation symbol is the main standard in the process of remote sensing image interpretation, remote sensing image characteristics and the actual object corresponding to the logical relationship is the basis of image interpretation key establishment. So, to establish a set of accurate interpretation marks mainly is to seize the characteristics of remote sensing image, remote sensing image characteristics mainly from tonal (target features in remote sensing image color and tone), shape (the shape of the target features in remote sensing image,
Table.I Land-use combined classification

\begin{tabular}{|c|c|c|c|}
\hline $\begin{array}{c}\text { Serial } \\
\text { Number }\end{array}$ & $\begin{array}{c}\text { Classification } \\
\text { Type }\end{array}$ & $\begin{array}{c}\text { Contains The Standard } \\
\text { Type }\end{array}$ & $\begin{array}{c}\text { Standard } \\
\text { Type } \\
\text { Number }\end{array}$ \\
\hline 0 & Bare Land & Bare Land & 127 \\
\hline 1 & Irrigated Land & Irrigated Land & 012 \\
\hline 2 & Dry Land & Dry Land & 013 \\
\hline 3 & Other Grass & Other Grass & 043 \\
\hline 4 & Natural Grassland & Natural Grassland & 041 \\
\hline 5 & Woodland & $\begin{array}{c}\text { Forest land, shrub, and } \\
\text { other woodlands }\end{array}$ & $\begin{array}{c}031, \\
032,033\end{array}$ \\
\hline 6 & Surface Of River & $\begin{array}{c}\text { Surface Of River } \\
\text { Surface Of Pits }\end{array}$ & 111 \\
\hline 7 & Surface Of Pits & $\begin{array}{c}\text { Lommercial and service } \\
\text { land, residential land, } \\
\text { industrial and mining } \\
\text { warehouse land }\end{array}$ & $05,06,07$ \\
\hline 8 & Construction & ind & \\
\hline
\end{tabular}

texture and size), and location (target features in remote sensing image spatial location) two aspects. During the information extraction of remote sensing image, color, tonal, shape, texture, size and spatial location characteristics, etc of the target object can be used as a direct interpretation symbol. Residential areas, roads and obvious indicator of artificial construction in image interpretation plays a supplementary role also can be used as indirect interpretation symbol of interpretation. At the same time we also referring to the classification system of subjects in the study area, in order to grasp the detailed information in the study area as much as possible.

Remote sensing images are based on spectral characteristics, the radiation characteristics, the characteristics of geometric features in a timely manner to reflect the feature information. first study area of visual interpretation must chose a piece of typical representative area, according to the imaging characteristics (shape, color, texture, etc.), using geology related laws, with a variety of remote sensing data, and combined with field survey to establish unified interpretation signs in the study area (Figure 2). Under the interpretation, control the scale of 1:100000. After completion of interpretation and field sampling verification, especially to verify the type of image feature is not obvious.

\section{STUdy AREA LAND USE REMOTE SENSING INFORMATION EXTRACTION AND ANALYSIS}

Remote sensing image is not only affected by the weather, terrain, ground objects spectrum characteristic, the influence of such factors as in the interpretation process (such as shadow removal, the training area selection, etc.), but are also influenced by man's subjective factors, which reduce the precision of remote sensing. Therefore, we in the process of interpretation some certain measures must be taken, such as increase the wild anchor point, using high quality remote sensing image, etc.) to minimize the error of interpretation, and 

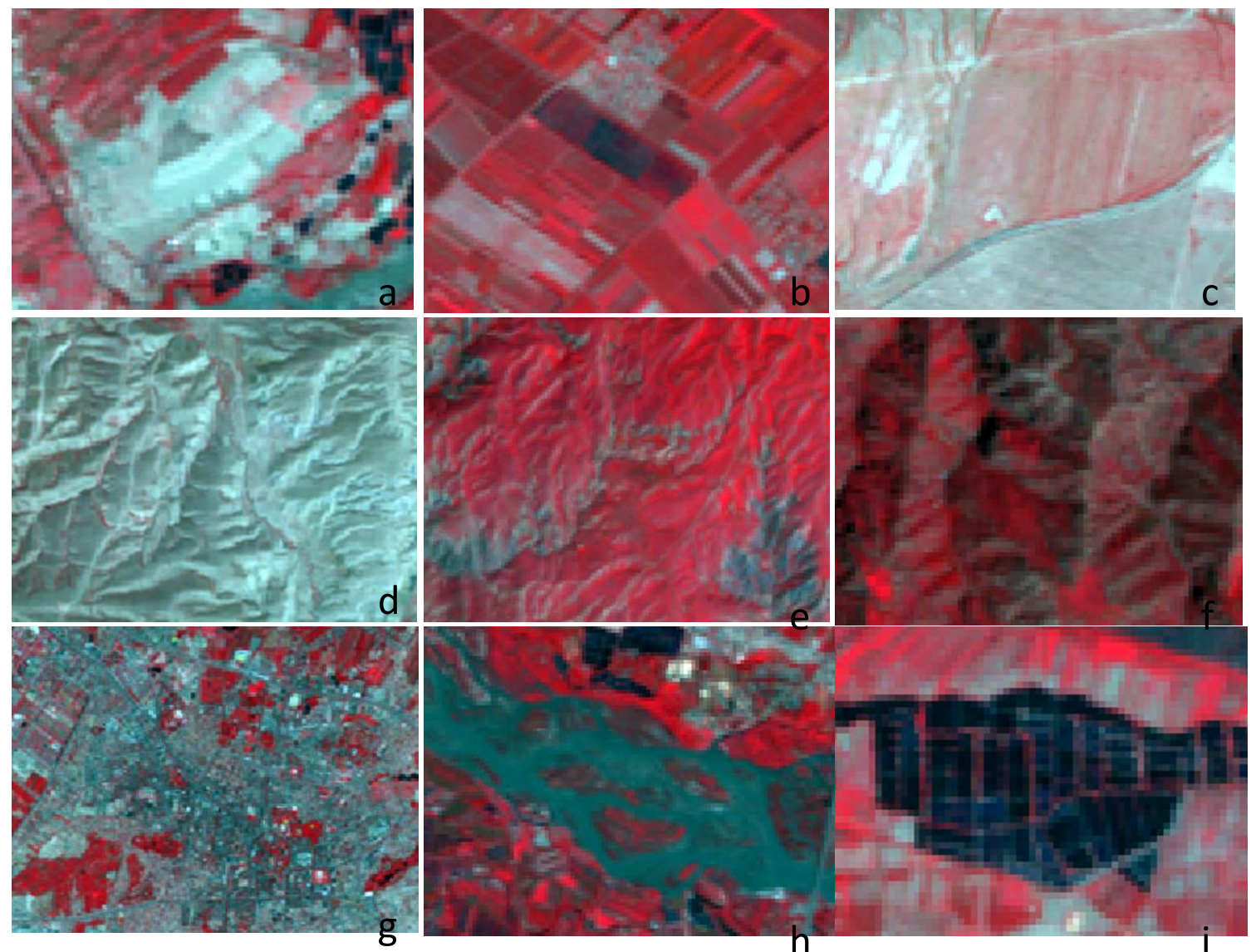

Figure.2 Interpretation signs image of study area

(Note: a bare land, b irrigated c dry land, $d$ other grassland, e natural grassland, $\mathrm{f}$, woodland, g, building land, $\mathrm{h}$ water surface, i pond water surface)

the interpretation of the results for accuracy assessment. In this project during the study period, the author investigated in the study area many times. In the investigation, we use GPS to locate and record anchor point information, in order to improve the precision of remote sensing image interpretation. At the same time the project is referred to GoogleEarth QUICKBIRD high spatial resolution remote sensing image, to assist remote sensing interpretation.

The data of land is used for man-machine interactive interpretation methods. For interpretation of land use map is stored in the MAPGIS environment for WT, WL, WP file format, and unified in the same projection and coordinate transformation.

Three periods of the study area is obtained by interpretation 1:100000 land use map, and the corresponding statistical information (Figure 3).

\section{LAND USE DyNAMIC ChANGE ANALYSIS IN THE STUDy AREA}

According to three periods of land cover analysis we obtained the stages in the study area land use dynamic variation (Figure 5). To be sure, the remote sensing image imaging time has much effect on the remote sensing information. This topic used the remote sensing images in 2000 vegetation development which was significantly much higher than in 1990 and 2010, the vegetation development degree. The reason may be that in 2000 rainfall condition is good, so good vegetation at the same time, the same area vegetation development. Therefore, this topic mainly compared with 2010 in 1990 of

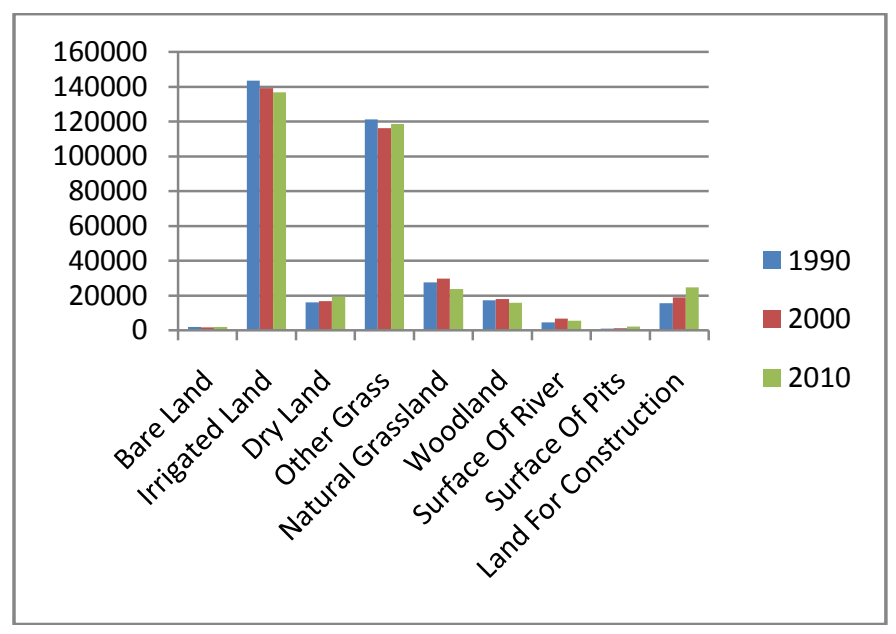

Figure. 3 Three periods of remote sensing image land-use number comparison chart of the study area (Unit: $\mathrm{hm}^{2}$ )

vegetative cover change. Statistical data from the figure 4 , area of irrigable land in 20 years in the study area decreased, other 
grass (mainly of weeds) , natural grassland and woodland area were reduced, construction land, dry land area increased, showing that human activity is directly related to land use change in the studied area. the great economic development of the region in 20 years are closely related, the urbanization process will inevitably cause town outward expansion, the city of the existing cultivated land resource into land for construction purposes[7].

Above is only part of the land utilization quantity change. As for the change reason and way, you will need to further analysis. This study changes in the types of land use transfer matrix which is used to analysis. Land use transfer matrix is the basis of analysis of the regional land use quantity change, using the overlay analysis of GIS, by two phase of the land use map; you can get the land use transfer matrix (Table II). Transfer matrix contains areas in different periods of land use quantity structure information and mutual transformation between various land use types at different times of the information. Can be seen from table 4, the types of land use change is the biggest mainly irrigated land, other grassland, natural grassland, surface of river and land for construction. Among them, the change is big of irrigable land into Land for construction 8543 hectares, natural grassland into other grass 5206 hectares, the other the grass to dry land 4948 hectares, other grass to irrigate 3263 hectares of land. This a series of transformations that the human production activities have greatly affected the region ecological environment, the region ecological environment from 1990 to 2010, has a tendency to decline.

\section{CONCLUSION}

Yiningarea , by 1990, 2000, 2010, the third phase of the remote sensing data for land use/cover analysis, established the database of land classification in 20 years. Combined with the GIS spatial analysis, the author obtained the land type conversion transfer matrix. Land use type change is the biggest mainly irrigated land, other grassland, natural grassland, surface of river and other land for construction. Among them, the change is big of irrigable land into Land for construction, 8543 hectares, natural grassland into other grass, 5206 hectares, the other the grass to dry land 4948 hectares, other grass to irrigate 3263 hectares of land. This a series of transformations that the human production activities have greatly affected the region ecological environment, the region ecological environment from 1990 to 2010, has a tendency to decline. With the development of Yining city urbanization, the increase of construction land use factors led the use of grass land into cultivated land to make up for deficiencies. Method of combining the remote sensing and GIS technology to analyze regional land use/cover, maximum limit for people to improve the efficiency of the use of land resources, to formulate conforms to the natural ecological conditions of the local planning policies, and provides the technical support and scientific basis.

\section{REFERENCES}

[1] JuJianghua, Wang Yan, "The application of remote sensing technology in land management," Geological Publishing House, Beijing. 2009,pp.123.

[2] You Xianxiang. "Remote sensing principle and the application in resources and environment,", China Forestry Publishing House, Beijing.2003,pp.384-385.

[3] Wang Qiao, Wang Wenjie, “ Macroscopic ecology based on remote sensing monitoring technology research". China Environment Science Press, Beijing. 2006,pp.1-3.

[4] ZHANG Yun-hong,WANG Dao-jie, “Changes in Land Use in the Upper Reaches of the Minjiang River and Their Effects on the Local Eco-environment", Journal of Southwest University(Natural Science Edition), vol.32(3),pp.103 108,2010 .

[5] SONG Xiang,YAN Chang-zhen, “ Land Use/Cover Change and Associated Effects on Eco-environment in Source Region of Yellow River", Journal of Desert Research, vol.29(6),pp.1049$1055,2009$.

[6] XIANG Wu-sheng,DING Tao, " Land Use/Cover Change and Its Influence on Eco-environment Benefit in Lijiang River Basin”, Hubei Agricultural Sciences, vol.50(5),pp.934-939,2011.

[7] The Appraisal and Analysis on Arable Land Intensive Use of Yining City in New Situation,Xinjiang Agricultural University, Urumqi,2011,pp.34-35.

Table. II The conversion of the area of land use types in the study area between 1990 and 2010 (Unit: $\mathrm{hm}^{2}$ )

\begin{tabular}{|c|c|c|c|c|c|c|c|c|c|}
\hline $\begin{array}{c}\text { 1990 } \\
\text { B10 }\end{array}$ & $\begin{array}{c}\text { Bare } \\
\text { land }\end{array}$ & $\begin{array}{c}\text { Irrigated } \\
\text { Land }\end{array}$ & Dry Land & $\begin{array}{c}\text { Other } \\
\text { Grass }\end{array}$ & $\begin{array}{c}\text { Natural } \\
\text { Grassland }\end{array}$ & Woodland & $\begin{array}{c}\text { Surface } \\
\text { Of River }\end{array}$ & $\begin{array}{c}\text { Surface } \\
\text { Of Pits }\end{array}$ & $\begin{array}{c}\text { Land For } \\
\text { Construction }\end{array}$ \\
\hline Bare land & 0 & 649 & 0 & 16 & 0 & 19 & & & 83 \\
\hline Irrigated Land & 808 & 0 & 1247 & 3263 & 93 & 884 & 35 & 120 & 0 \\
\hline Dry Land & & 382 & 0 & 4948 & 173 & 0 & 18 & 0 & 0 \\
\hline Other Grass & 7 & 886 & 717 & 0 & 5206 & 1292 & 673 & 0 & 0 \\
\hline $\begin{array}{c}\text { Natural } \\
\text { Grassland }\end{array}$ & 0 & 149 & 0 & 662 & 0 & 1057 & 28 & 0 & 0 \\
\hline Woodland & 62 & 1786 & 0 & 475 & 19 & 0 & 774 & 10 & 3 \\
\hline $\begin{array}{c}\text { Surface Of } \\
\text { River }\end{array}$ & 51 & 1041 & 0 & 482 & 0 & 134 & 0 & 0 & 0 \\
\hline Surface Of Pits & 3 & 1294 & 0 & 0 & 0 & 30 & 50 & 96 & 0 \\
\hline $\begin{array}{c}\text { Land For } \\
\text { Construction }\end{array}$ & 56 & 8543 & 232 & 1439 & 0 & 85 & 1 & 8 & 0 \\
\hline
\end{tabular}

